\title{
LA REHABILITACIÓN DE LA CASA DE SAN ISIDRO EN MADRID Y LOS PARAGUAS CURVOS
}

\author{
(THE RECONSTITUTION OF S. ISIDRO'S HOUSE IN MADRID \\ AND THE CURVED UMBRELLAS)
}

Valentín Quintas Ripoll, Arquitecto

ESPAÑA

Fecha de recepción: 22-II-99

\section{RESUMEN}

En este artículo se describe la reconstrucción de la casa de San Isidro en Madrid y del palacio de los Condes de Paredes, que la envolvía desde el siglo XVI. La parte posterior del edificio se ha utilizado para albergar las salas del Museo de Madrid Medieval. Estas salas están cubiertas con láminas de hormigón armado, cuya superficie está formada por paraboloides hiperbólicos con el borde curvo.

\section{SUMMARY}

In this paper the reconstitution of $S$. Isidro's house at Madrid and the XVI th century palace that surrounded it, is described. The back part of this building has been used to acomodate the Museum of Medieval Madrid. These spaces are roofed by hyperbolic paraboloid shells with curved boundaries.

\section{ANTECEDENTESHISTÓRICOS}

Según una tradición antiquísima, San Isidro vivió y murió en el siglo XII, en la casa de la plaza de San Andrés, llamada "Casa de San Isidro". Efectivamente, la zona del solar donde se supone habitó el santo, se encuentra por debajo del nivel actual del terreno, tal y como ocurre en los asentamientos muy antiguos. En el mismo solar se encuentra un profundo pozo de manantial, todavía en uso, que es, según la misma tradición, donde San Isidro hizo milagrosamente subir sus aguas para salvar a su hijo. La casa debió de conservarse después de la muerte del santo.

En cualquier caso, se sabe que en tiempos de Enrique IV vivía en ese lugar Juan de Luján "el Bueno" [1] , no la familia Vargas como se ha dicho erróneamente. Su hijo, el Licenciado Antonio de Luján, según Quintana [2], rehizo totalmente, en el estilo plateresco de la época de Carlos V, la casa de su padre. Se supone que el arquitecto fue Luis de Vega, ya que existe una semejanza de estilo extraordinaria entre el "patio de la Reina" [3] del Alcázar de Madrid -según grabados de la época- y los restos que se han conservado del patio de la "Casa de San Isidro", contemporáneos a la obra del Alcázar. En tier ros de Felipe II pasó a ser Nunciatura [4], debido a ' 1 . Regalía de Aposento", que obligaba a los propietarios a ceder sus casas al cuerpo diplomático y los funciunarios de la Corte. Existe una descripción detallada del edificio en esa época, en la que se habla de dos escaleras, una capilla y un patio. Quintana, en 1623, cuenta que en esa casa "se ve un aposento bajo con su chimenea, a lo antiguo, donde se cree que vivió el bendito santo". Efectivamente, se ha encontrado encima de la bóveda de la capilla un forjado pintado del s. XVI, con su correspondiente hueco de chimenea. En el s. XVIII la nunciatura había pasado al edificio de la calle del Nuncio y los Condes de Paredes, descendientes de Catalina de Luján, habían recuperado el edificio. A finales de ese siglo se rehizo la capilla, con una bóveda de madera y estuco, pintada al fresco por Zacarías González Velázquez (figura 1), que es lo único que se conserva intacto del antiguo palacio.

El palacio del Licenciado Antonio de Luján, debió, sin embargo, llegar prácticamente sin modificaciones al año 

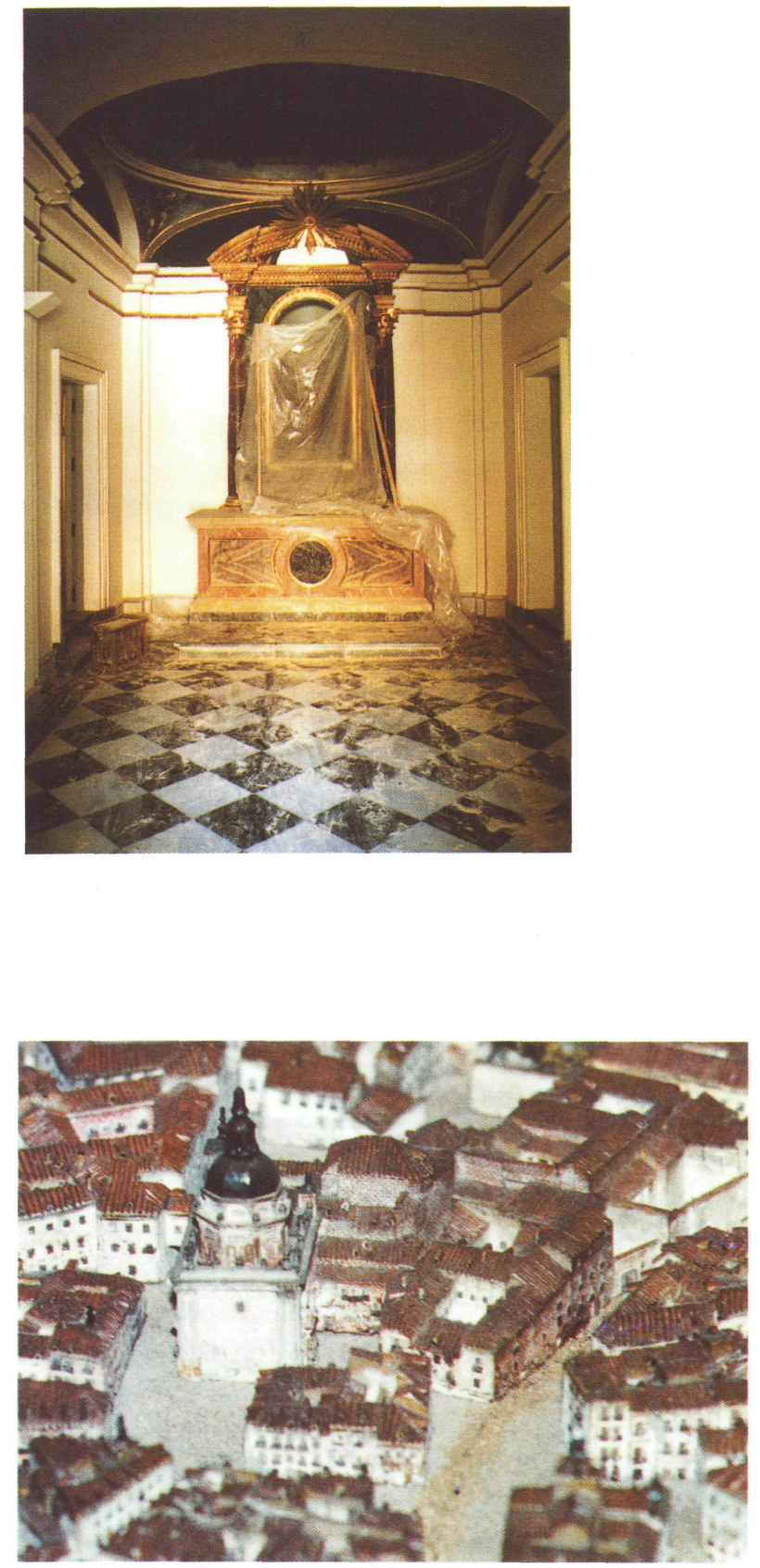

Figura 2.- La "Casa de San Isidro" y San Andrés, según la maqueta de León Gil del Palacio, de 1830.

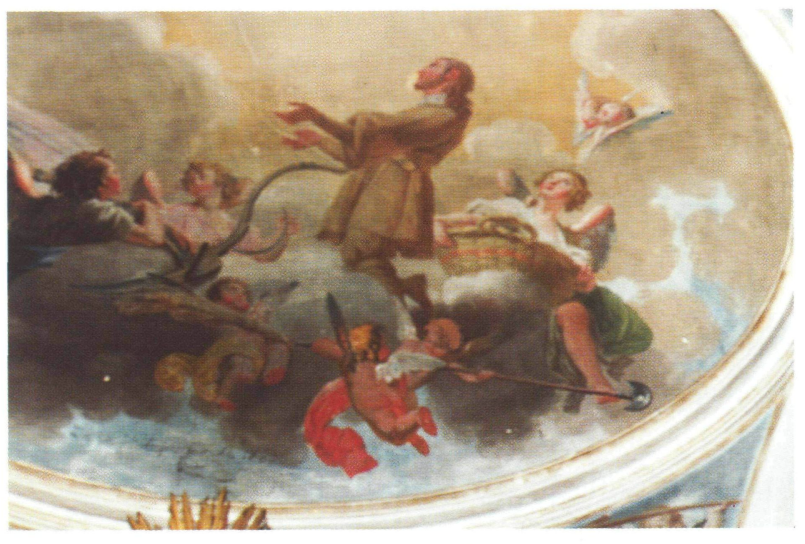

Figura 1.- La capilla durante la restauración.

1830, cuando León Gil del Palacio hizo una detalladísima maqueta de Madrid. En ella se observa (figura 2) que el palacio se componía de dos alas más altas que rodean el lugar que ocupa la capilla y la casa de San Isidro y otra, posterior, que cerraba el patio plateresco con los intercolumnios cegados, sustituyendo huecos por ventanas. La parte trasera del palacio, que debió ser su antiguo jardín, está ocupada por un edificio de viviendas de cuatro alturas. En el siglo XIX sufrió una nueva reforma, consistente en el añadido de una planta a la "Casa de San Isidro", que hizo desaparecer la diferencia de alturas entre las dos alas del palacio y un revoco de la fachada que ocultó su aparejo. Los descendientes de los Condes de Paredes continuaron habitándolo hasta la guerra civil de 1936. A partir de entonces lo alquilaron. Siguió, sin embargo, celebrándose todos los días de San Isidro una antiquísima ceremonia,consistente en una misa en la capilla y en la distribución, en el zaguán de la casa, de agua del pozo del milagro. En 1971, se declaró en ruina y se procedió a su derribo. En él aparecieron las columnas y los arquitrabes del patio plateresco. El arquitecto municipal de la zona, Juan López Jaén, consiguió salvar estos restos, la capilla y el pozo. Más adelante, el Ayuntamiento expropió el solar y decidió dedicarlo a "Museo de San Isidro y el Madrid Medieval", para lo que convocó un concurso de ideas. En el anteproyecto ganador se proponía (figura 3) reconstruir la "Casa de San Isidro", tal y como estaba antes del derribo y ocupar parcialmente la parte posterior, que, en época de los Lujanes, habł́a sido un jardín, con una serie de salas para el Museo eubiertas con láminas en paraboloide hiperbólico. El desarrollo de ese anteproyecto es lo que se describe a continuación.

http://informesdelaconstruccion.revistas.csic.es 


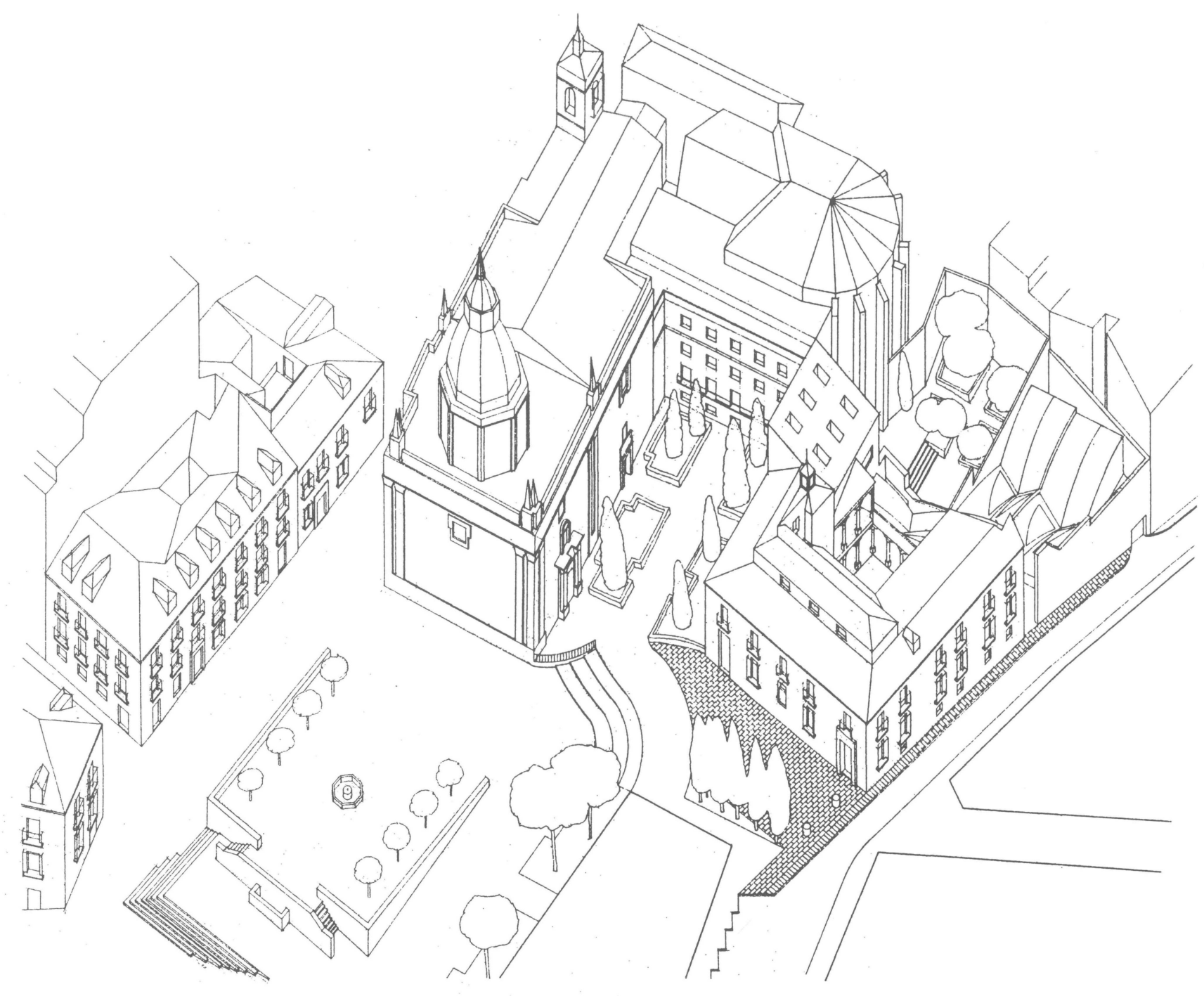

Figura 3.- Anteproyecto ganador del concurso del Museo de San Isidro.

\section{LAREEDIFICACIÓN}

Se decidió reedificar todos los elementos del viejo palacio de los Lujanes de los que se tuviera total seguridad de su forma. Para ello se disponía de la maqueta de León Gil del Palacio, de la excavación arqueológica (figura 4) que había puesto al descubierto la cimentación del patio y las fachadas y de los planos del expediente de derribo. Éstos consistían en una planta y dos alzados, con las modificaciones del s. XIX. Se pudo comprobar, por los restos de los muros, que el palacio tenía una construcción de hiladas de ladrillo con cajeados de pedernal, que era la clásica de Madrid en los siglos XVI y XVII, como se puede observar todavía en la Casa de Cisneros, las casas de los Lujanes en la Plaza de la Villa y la parte más antigua de las Descalzas Reales, todos ellos edificios coetáneos a la Casa de San Isidro. Curiosamente, la única parte del edificio que no tenía este tipo de construcción era la capilla, construida con muros de tapial. Esto demostraba, de nuevo, que la Casa de San Isidro, propiamente dicha, era anterior al siglo XVI y que, al construir las dos alas que la rodeaban, los

(c) Consejo Superior de Investigaciones Científicas

Licencia Creative Commons 3.0 España (by-nc)
Lujanes habían intentado respetar esa construcción más antigua, por veneración al santo. Por todo ello, se hizo más interesante reedificar la fachada tal y como aparecía en la maqueta de León Gil del Palacio. Esto fue relativamente sencillo: se podía conocer la disposición de los huecos, por el expediente de derribo (figura 5) y los volúmenes, por la maqueta. Tampoco hubo gran dificultad en dibujar los detalles de rejería y dinteles (figura 6), ya que la rejería y los capialzados de huecos en las construcciones del viejo Madrid tienen una tipología muy constante.

La excavación arqueológica reveló la existencia de multitud de silos árabes en el terreno, que han aportado material muy interesante: vajilla hispano-musulmana, una pequeña maqueta de una puerta árabe de muralla, una pieza de ajedrez, etc. Desde el punto de vista estructural, sin embargo, esto producía un grave problema ya que la resistencia del terreno variaba enormemente de un puntōà otro.

Se decidió que los muros de fachada fueran trasdosados por otro de hormigón armado, cuya rigidez y resistencia, http://informesdelaconstruccion.revistas.csic.es 


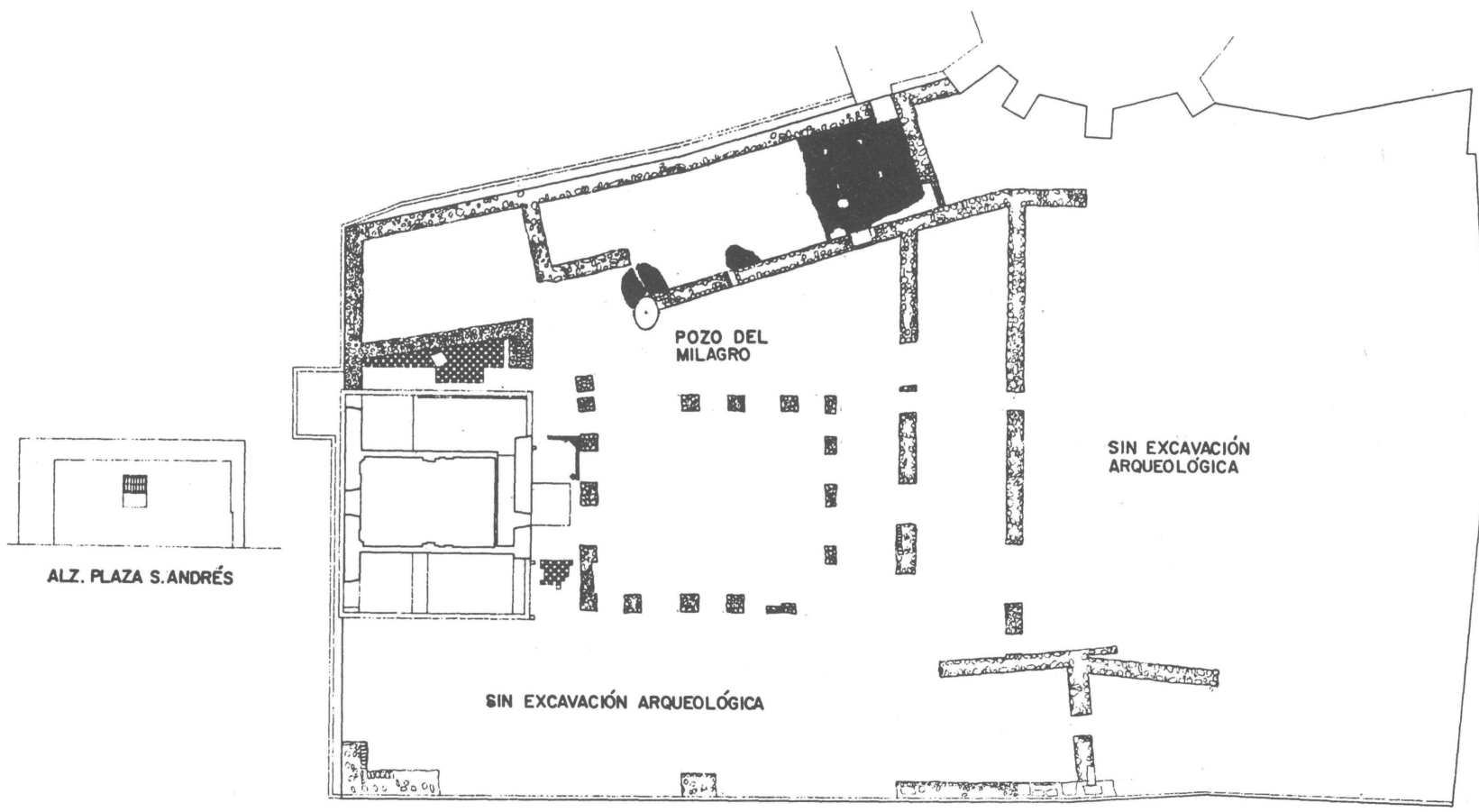

Figura 4.- Excavación arqueológica de la "Casa de San Isidro".
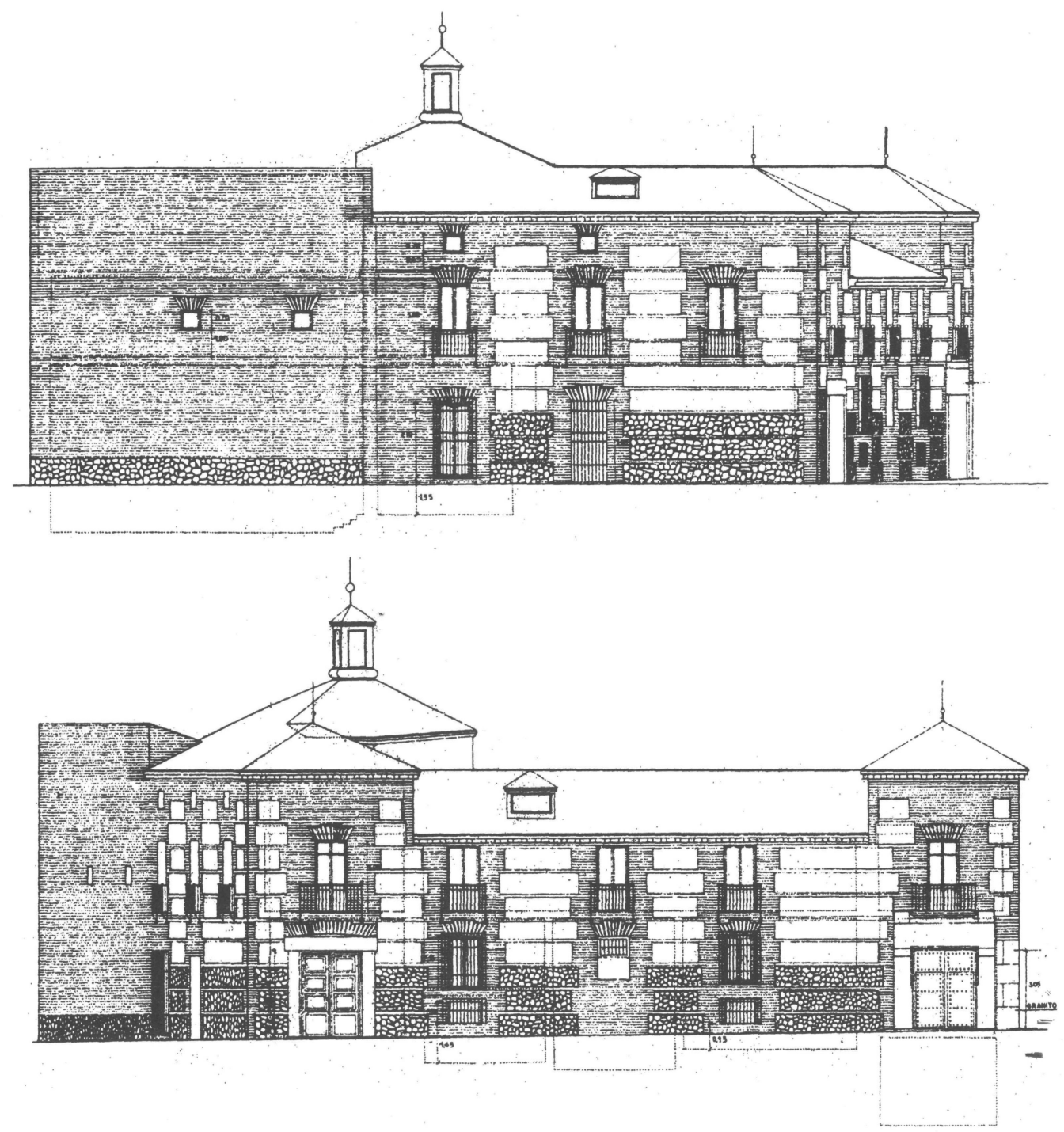

Figura 5.- Alzados reedificados de la "Casa de San Isidro". 

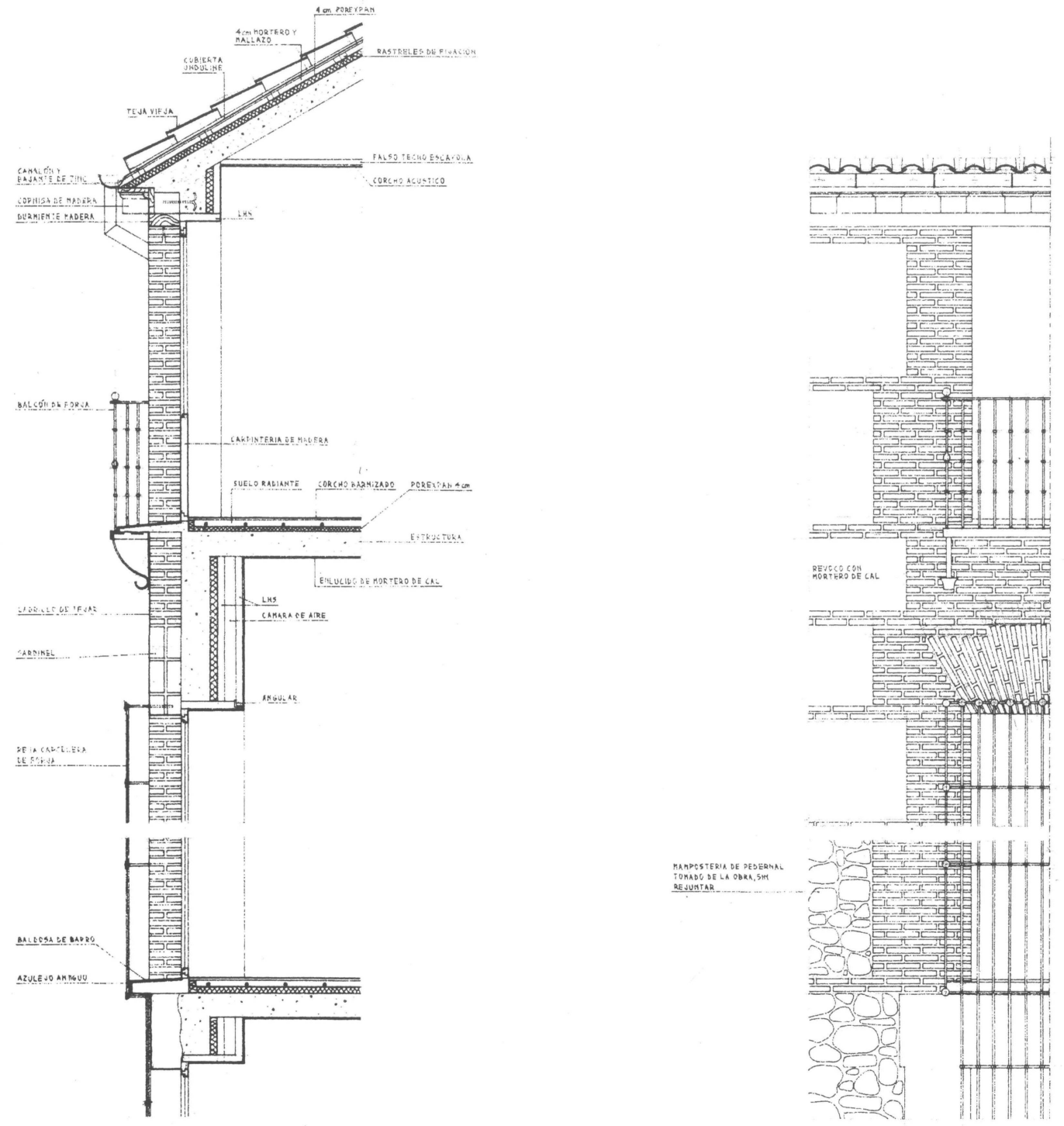

Figura 6.- Detalles de fachada.

al trabajar como viga pared, permitía amortiguar totalmente los asientos diferenciales. La capilla se envolvió cuidadosamente en una estructura mixta de hormigón y acero, una vez recalzados sus cimientos.

Finalmente, tampoco existieron grandes dificultades en reedificar el patio plateresco, ya que se conocía exactamente la posición de los pilares por la excavación y se habían conservado casi todos los dinteles, los fustes, las zapatas y los capiteles. Para no añadir una estructura que perturbaría la ligera plástica de la columnata, se decidió que fueran los propios fustes de piedra los que soportaran la carga de los forjados del patio. En el resto del edificio sólo se reedificaron los espacios, ya que no se disponía de datos para reconstruir los detalles.

Tampoco se disponía de información sobre la parte trasera del edificio. Se decidió simplemente señalar sus límites con un cerramiento y cubrirlo con una gran lámina en

(c) Consejo Superior de Investigaciones Científicas

Licencia Creative Commons 3.0 España (by-nc) paraboloide hiperbólico de hormigón armado. Las salas contiguas que ocupan parcialmente el antiguo jardín se cubrieron también con paraboloides hiperbólicos. El resto, se dejó como un jardín, desde el que se podía contemplar el magnífico volumen que forma el ábside de la capilla del Obispo (figuras 7 y 8 )

\section{ALGOSOBRE PARABOLOIDES HIPERBÓLICOS}

Antes de entrar en la descripción de las nuevas salas del Museo conviene señalar algunos conceptos fundamentales sobre los paraboloides hiperbólicos. Un paraboloide hiperbólico es la superficie generada al desplazarse una parábola invertida, sobre otra que no lo está. Hasta aquí podría suponerse que esta superficie es una sūperficie de traslación "anticlástica", como muchas otrā̄ que se pueden imaginar. Sin embargo, el paraboloide hiperbólico tiene una cualidad que lo hace distinto de cualquier otra http://informesdelaconstruccion.revistas.csic.es 


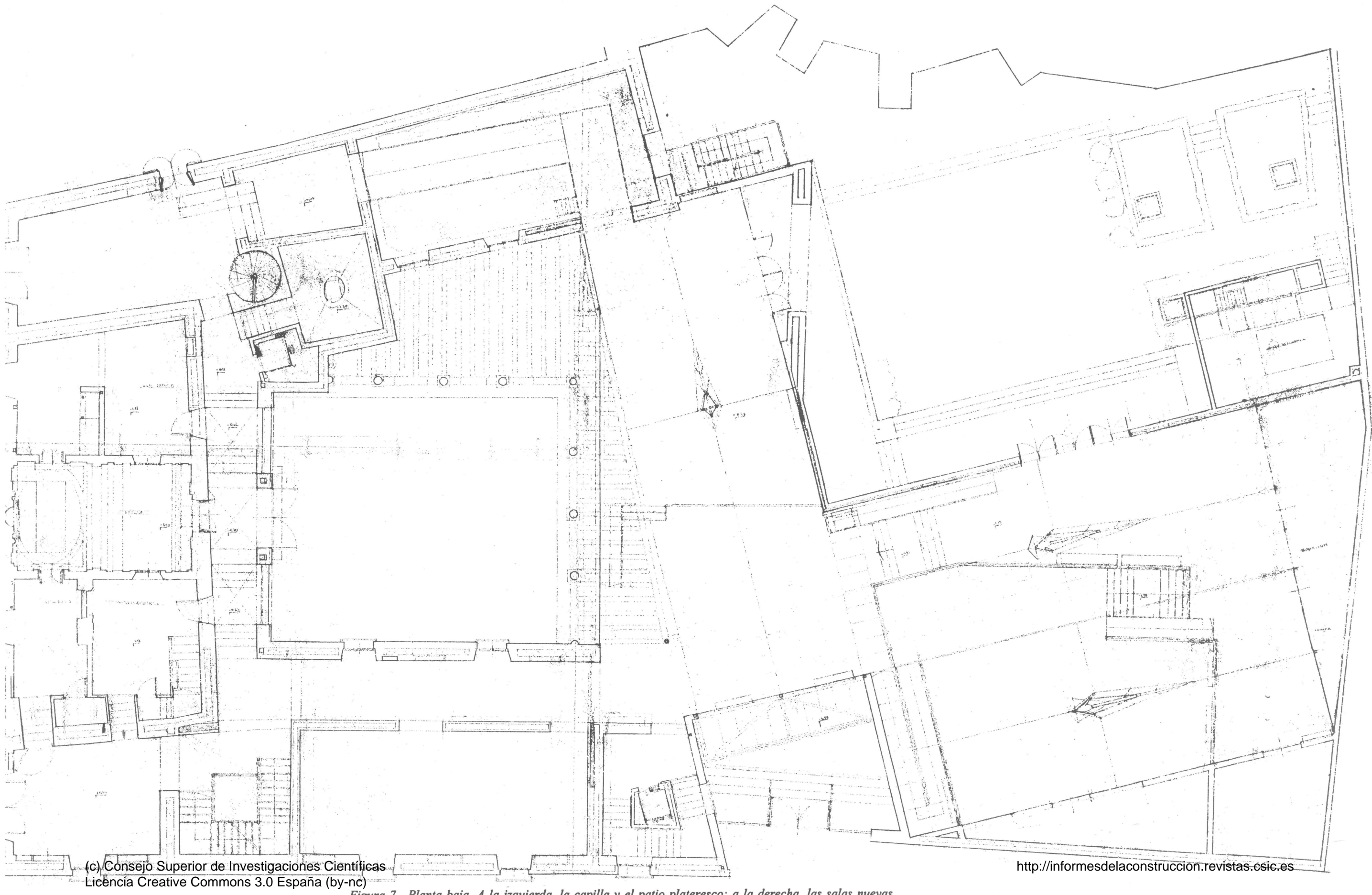

Figura 7.- Planta baja. A la izquierda, la capilla y el patio plateresco; a la derecha, las salas nuevas. 

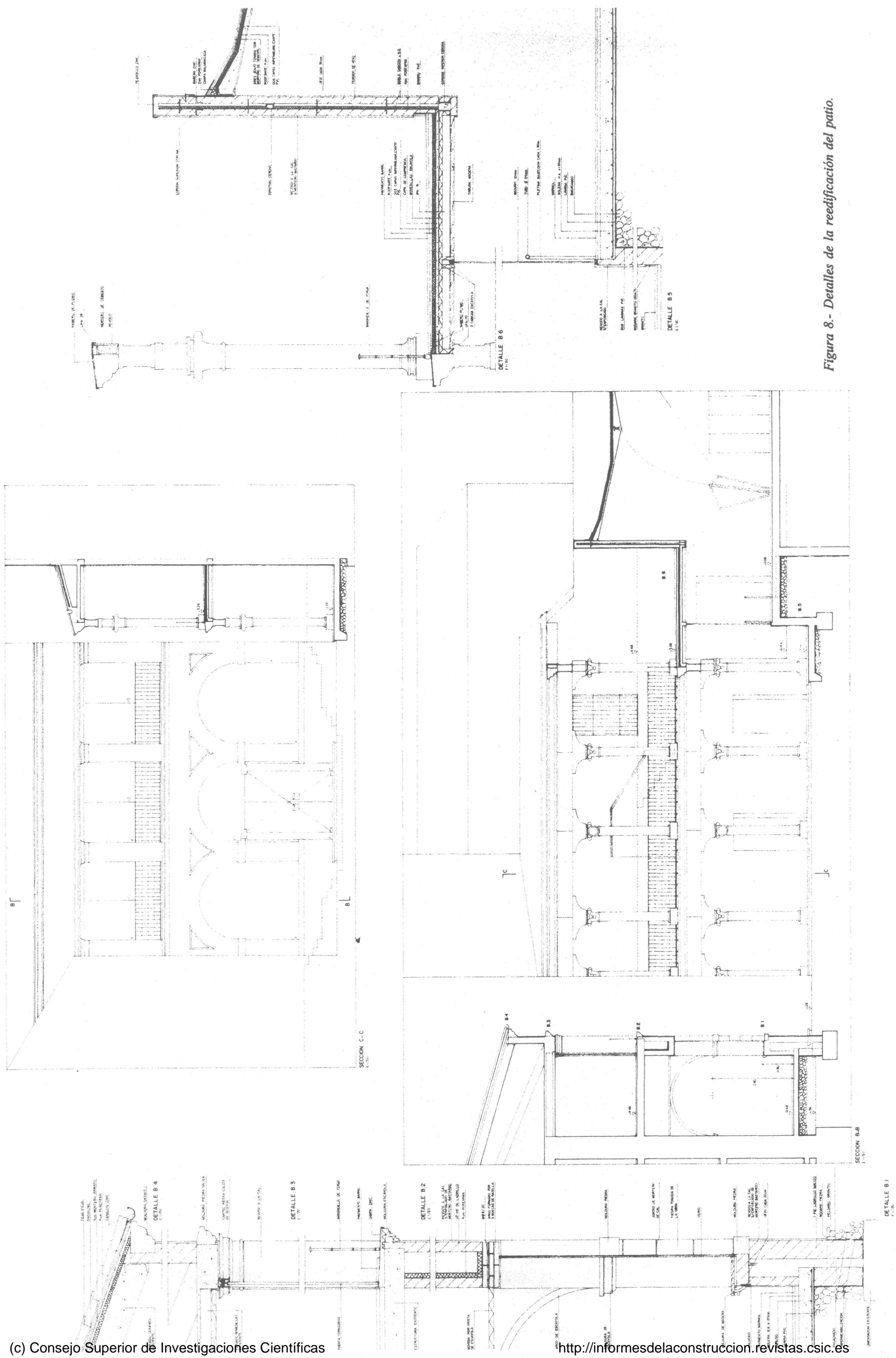
superficie de traslación: es, además, una superficie reglada. Si giramos los ejes que estaban en la dirección de las parábolas generatrices, hasta colocarlas en los planos que son bisectrices a esas parábolas, nos damos cuenta que la superficie también está generada por dos familias de rectas que se van inclinando, cada vez más, a medida que nos vamos alejando de los ejes (figura 9). Esta cualidad hizo a Gaudí decir -de manera bastante incomprensibleque el paraboloide hiperbólico era la expresión geométrica de la Santísima Trinidad y, por eso, intentó utilizarlo para la bóvedas de la Sagrada Familia. En cualquier caso, y bajo el punto de vista de los nuevos ejes, la ecuación del paraboloide es la más sencilla -como decía Candelade la geometría analítica aplicada a superficies:

$$
z=\frac{x y}{c}
$$

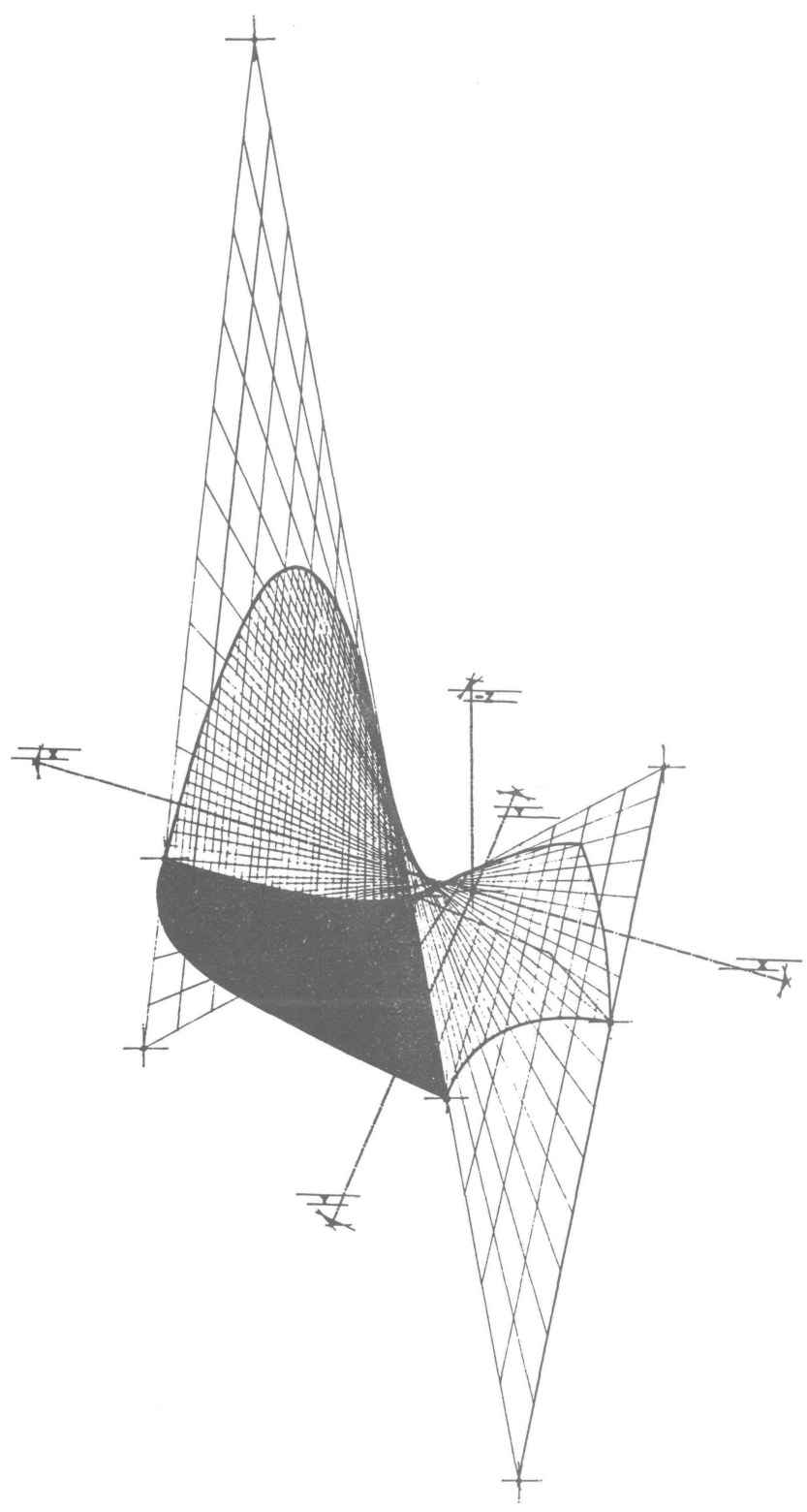

Figura 9.- Un paraboloide hiperbólico según Candela (tomado de la obra de Faber [6]).
Ya que no es más que la expresión de una recta, cuya tangente en dirección $\mathrm{x}$, es, por ejemplo:

$$
\operatorname{tg} \gamma_{x}=\frac{\delta z}{\delta x}=\frac{y}{c}
$$

O sea, aumenta a medida que "y" aumenta. El valor "c" se llama "parámetro del paraboloide" y es básico conocerlo, para poder definir la geometría de la superficie. Si las dos parábolas que definen la curva son distintas, las dos familias de rectas forman un ángulo cualquiera $\varpi$. Si las dos parábolas son iguales, forman un ángulo de $90^{\circ}$ y el paraboloide se dice que es "equilátero". Naturalmente, si queremos utilizar la ecuación de la superficie en un paraboloide no equilátero, debemos colocar los ejes formando un ángulo $\varpi$ distinto de $90^{\circ}$, por lo que, para definir los valores de $\mathrm{x}$ e y, debemos utilizar coordenadas oblicuas y, por supuesto, el valor de $\varpi$ es imprescindible para poder definir la superficie.

En 1953, Félix Candela [6] se atrevió, por primera vez, a construir lo que, en adelante, se llamó "un paraguas". Es una estructura formada por cuatro fragmentos de paraboloide equilátero, cortados por los ejes y unidos entre sí por las generatrices inclinadas (figura 10a). Los teóricos habían augurado que los bordes, bajo su propio peso, arrastrarían toda la lámina hacia abajo, haciéndola colapsar. Sin embargo, la estructura se mantuvo perfectamente y es, de hecho, la forma de lámina de hormigón armado que más se ha construido hasta la fecha. $\mathrm{Al}$ estar formada por paraboloides equiláteros, los bordes del paraguas son rectos, horizontales y perpendiculares entre sí. En el Museo de San Isidro, se intentó hacer un "paraguas", con dos bordes rectos y dos bordes curvos (figura 10b). Esto sólo puede conseguirse si el paraboloide no es equilátero y, por tanto, los ejes de coordenadas y las generatrices rectas forman un ángulo $\varpi$. Si observamos la figura $10 \mathrm{~b}$, podemos ver enseguida que es bastante fácil determinar el parámetro "c" y el ángulo " $\varpi$ " que forman las generatrices rectas, si se definen las dimensiones " $a$ " y "b" en planta de cada fragmento de paraboloide y las alturas " $\mathrm{z}_{\mathrm{b}}$ " $\mathrm{y}$ " $\mathrm{z}_{0}$ " de los lados opuestos a los ejes $\mathrm{y}$, por tanto, el "canto", o altura en alzado de la sección donde la lámina se apoya, "h". En efecto, como la ecuación del paraboloide sigue siendo: $\mathrm{z}=\mathrm{xy} / \mathrm{c}$, aunque ahora hay que medir " $x$ " e " $y$ " en ejes oblicuos, tenemos:

para el punto $E: z=z_{0}$

$$
\begin{aligned}
& x=b \operatorname{tg}\left(\varpi-90^{\circ}\right)=b / \operatorname{tg} \varpi ; \\
& y=b \cos \left(\varpi-90^{\circ}\right)=b / \operatorname{sen} \varpi
\end{aligned}
$$

Por tanto, sustituyendo, queda:

$$
z_{0}=\frac{b^{2}}{c \operatorname{tg} \varpi \operatorname{sen} \varpi}
$$

para el punto $\mathrm{F}: \mathrm{z}=\mathrm{z}_{\mathrm{a}}$

$$
x=b / \operatorname{tg} \varpi+a \quad y=b / \text { sen } \varpi, \text { y queda: }
$$

http://informesdelaconstruccion.revistas.csic.es 

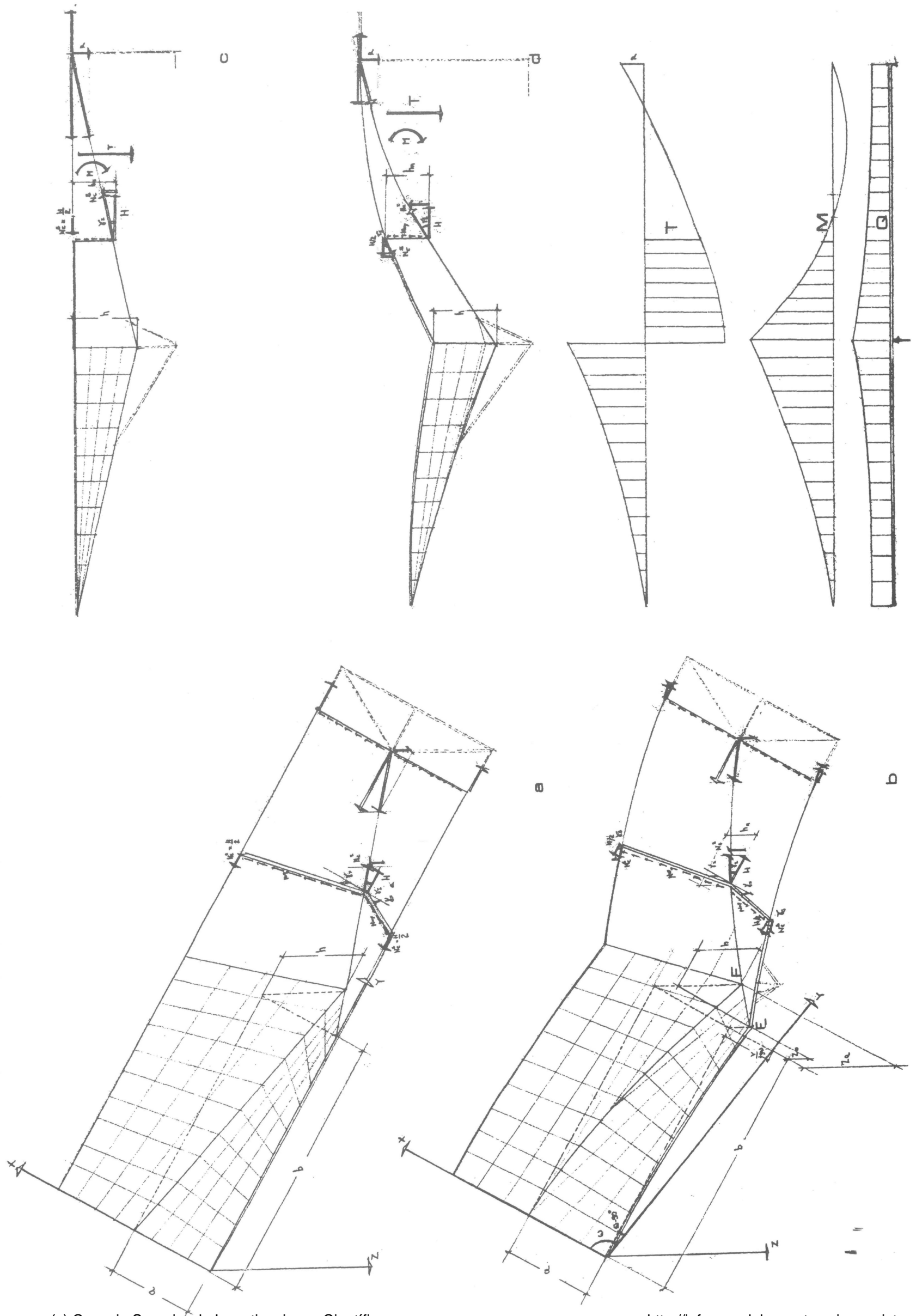

(c) Consejo Superior de Investigaciones Científicas Licencia Creative Commons 3.0 España (by-nc) 


$$
z_{a}=\frac{b^{2}}{c \operatorname{tg} \varpi \operatorname{sen} \varpi}+\frac{a b}{c \operatorname{sen} \varpi}
$$

por tanto, el "canto" h, vale:

$$
h=z_{a}-z_{0}=a b / c \operatorname{sen} \varpi
$$

sustituyendo esta ecuación en la de $\mathrm{z}_{0}$, obtenemos:

$\operatorname{tg} \varpi=\mathrm{h} b / \mathrm{a} \mathrm{z}_{0} \mathrm{y}$, conocido $\varpi$, podemos despejar c de la misma ecuación : $c=a b / h$ sen $\varpi$. Las dos grandes curvas que definen los bordes largos se obtienen sustituyendo las coordenadas de los lados en la ecuación del paraboloide. La curva exterior es para: $\mathrm{x}=\mathrm{y} \operatorname{sen}(90-\varpi)=\mathrm{y} \cos \varpi \mathrm{y}$ queda:

$$
z=\frac{\cos \varpi}{c} y^{2}
$$

La curva interior es para $\mathrm{x}=\mathrm{y} \cos \boldsymbol{\omega}+\mathrm{a}$, $\mathrm{y}$ queda:

$$
z=\frac{\cos \varpi}{c} y^{2}+\frac{a}{c} y
$$

vemos que las dos curvas son parábolas, aunque, por supuesto, no son las parábolas generatrices de la superficie. La geometría de la superficie se puede, pues, definir en todos los puntos, con bastante facilidad.

\section{LOS PARAGUAS Y LAS VIGAS PERFECTAS}

Candela obtuvo los esfuerzos de membrana para casi cualquier tipo de carga y de paraboloide ([6] págs. 19 a 35) en 1960. En el caso de los paraboloides del Museo, se pueden aplicar estas fórmulas para peso propio, carga de nieve, el ángulo $\varpi$ obtenido y las condiciones de borde curvo del caso. Sin embargo, hay una forma más sencilla de calcular la estructura de forma aproximada y que, además, permite darnos cuenta de qué es exactamente lo que necesita la lámina para mantenerse en equilibrio. También se debe a Candela [7]. Cuando empezó a construir paraboloides más complicados, se dio cuenta que, de forma aproximada, los paraboloides trabajan como vigas "perfectas". Si somos capaces de dibujar los diagramas de momentos y cortantes globales de los paraguas, al considerarlos como vigas laminares de sección variable (figura 10d)-lo que normalmente es muy sencillo porque, desde el punto de vista global, o son dos ménsulas unidas a un pilar, o es una viga apoyada en dos soportes con un voladizo, como en la figura $10 \mathrm{~d}-$, los dos bordes superiores $y$ el inferior deben generar un par de fuerzas horizontales $\mathrm{H}$ y de brazo de palanca $h_{c}$, que contrarrestaría el momento global $\mathrm{M}$ y cuya proyección, en dirección a los bordes, nos da los esfuerzos de los elementos de borde $N_{c}^{s}$ y $N_{c}^{\prime}$

$$
H=\frac{M}{h_{c}} ; N_{c}^{s}=\frac{H}{2 \cos r_{s}} ; N_{c}^{\prime}=\frac{H}{\cos r_{1}}
$$

con lo que se resiste el momento flector $\mathrm{M}$ de forma "perfecta", es decir, con dos barras separadas entre sí por el canto $h$, exactamente igual que en una celosía.
El cortante debe resistirlo la lámina, que, en este caso, sustituye al triangulado de la celosía, con una resultante de tensiones, por unidad de espesor, Nxy. Sin embargo, al estar los esfuerzos de los elementos de borde inclinados, producen dos componentes verticales, que, en el caso de los paraboloides del Museo de San Isidro, eran, una, en el sentido contrario del cortante, de valor $\mathrm{Htg} \gamma_{1}$ y dos, en el sentido del cortante, de valor $\mathrm{H} / 2 \operatorname{tg} \gamma_{\mathrm{s}}$

La lámina debe, pues, resistir un cortante:

$$
T-T_{1}=T-H \operatorname{tg} \gamma_{1}+H \operatorname{tg} \gamma_{s}
$$

Con las componentes verticales de la Nxy. Si suponemos que son constantes debe ser, si llamamos "s" a la longitud de la lámina seccionada:

2 Nxy s sen $\gamma_{x}=2 N x y h_{c}=T-T_{1}$, con lo que tenemos, de forma aproximada, el valor de las resultantes de tensiones tangenciales que debe resistir la lámina:

$$
N x y=\frac{T-H \operatorname{tg} \gamma_{1}+H \operatorname{tg} \gamma_{s}}{2 h c}
$$

se puede comprobar que este análisis [7] es exacto para el caso de paraguas "equiláteros", como el de la figura 10a, con carga de nieve, y sólo aproximado para los paraguas curvos del Museo de San Isidro, en el que, además, el peso propio es importante.

Sin embargo, cuando se comprobó este análisis por el método de los elementos finitos (figura11) se obtuvieron resultados semejantes. El estudio global de los paraguas como vigas permite, además, darse cuenta de los bordes que necesita la estructura para mantenerse en equilibrio. Por ejemplo, en los paraboloides del Museo se puede ver que si la estructura es, globalmente, una viga con dos apoyos y un voladizo, en el apoyo exterior los esfuerzos de los elementos de borde no pueden ser nulos. En efecto, al ser la lámina horizontal en ese punto, las tensiones tangenciales de membrana no pueden contribuir a transmitir la reacción. Los únicos elementos que pueden transmitirla son los de borde (figura 10c), si suponemos que las tensiones normales son nulas. Hubo que añadir a ese borde una celosía horizontal que contrarrestase las componentes horizontales de estos esfuerzos, que, por supuesto, se anulaban entre sí a lo largo del borde.

\section{LA CONSTRUCCIÓN}

A pesar de su buen funcionamiento, los paraguas, desde el principio, mostraron una fuerte tendencia a flectar en las esquinas. La razón de este fenómēno es, en realidad, la que había llevado a los teóricos a stuponer que los paraguas eran inviables: A pesar de estar los bordes horizontales traccionados y, por lo tanto, tener menos flecha que la que 

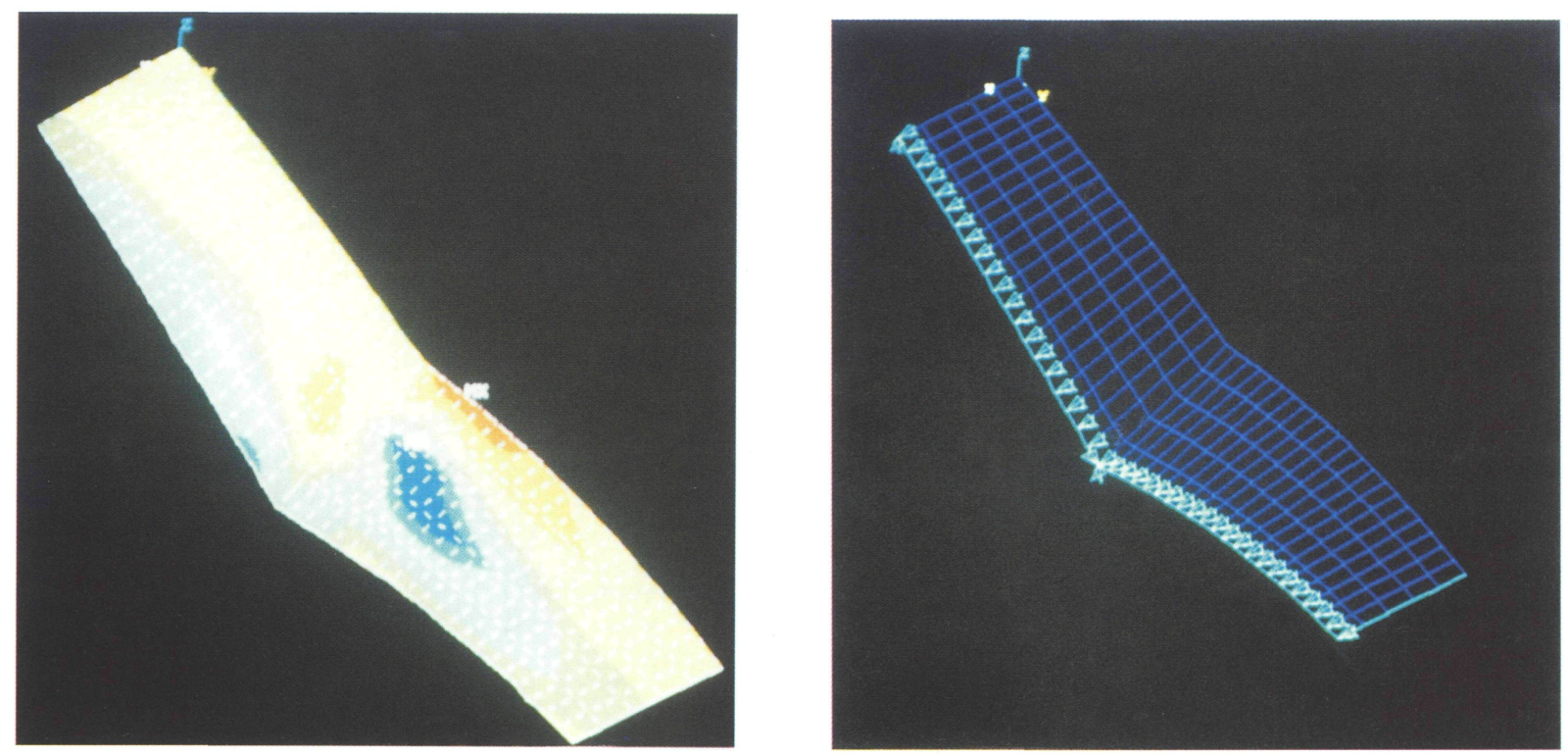

Figura 11.- Análisis de una de las láminas por elementos finitos.

aparecería si no tuviesen esfuerzos normales de tracción, los elementos de borde deben resistir su propio peso y su propia flecha. Estos elementos son: una pequeña barra de $10 \times 10 \mathrm{~cm}$, con armadura de tracción y trabajando como voladizos, con una luz próxima a los $6 \mathrm{~m}$. La flecha, pues, parecía inevitable, hasta que Ruiz-Castillo y Ucelay sustituyeron el elemento de borde de hormigón armado por perfiles laminados en U, con las armáduras de la lámina soldadas al alma. En los muchos paraguas que estos arquitectos construyeron en los alrededores de Madrid, las flechas se volvieron, con este sistema, imperceptibles. La razón de su éxito es que la disminución de flecha, debida a la tracción, es inversamente proporcional a la carga crítica del elemento de borde y ésta, a su vez, es directamente proporcional al momento de inercia de la sección. Hay que buscar, pues, un elemento que tenga, a la vez, momento de inercia pequeño y rigidez a flexión; algo muy difícil de hallar, salvo en perfiles laminados pequeños, que tienen rigidez suficiente, al estar construido a base de un material con un módulo de Young alto y un momento de inercia y, por tanto, una carga crítica pequeña.

Los paraguas ideales son, pues, estructuras mixtas. En los paraguas curvos del Museo se decidió llevar este concepto hasta el final. No sólo se hicieron los bordes con perfiles en $U$ curvados en taller, sino que las aristas interiores también se realizaron del mismo material (figura 12). La arista curva interior y las dos aristas rectas (c) Consejo Superior de Investigaciones Científicas Licencia Creative Commons 3.0 España (by-nc) -que trabajan predominantemente a compresión- se formaron con dos UPN unidos con tubos, exactamente igual que unos pilares empresillados.

El sistema mostró ventajas no sólo desde el punto de vista estructural, sino también desde el punto de vista de la facilidad del proceso constructivo. Lo que hace difícil construir el encofrado de una lámina no es la construcción en sí, sino su replanteo, que exige la presencia de un carpintero experimentado, más aún cuando tienen los bordes curvos. Si los bordes se traen prefabricados de taller, la geometría de la estructura queda fijada, sin más que colocar los perfiles laminados en posición (figura 13a). El resto es, sencillamente, un problema sólo ligeramente más complicado que el de realizar el encofrado de una losa (figura 13b). En la obra del Museo de San Isidro, bastó la presencia del cerrajero que había realizado los perfiles de borde y de una cuadrilla, cuya única experiencia había sido construir losas de aparcamiento, para realizar el encofrado y colocar la armadura en dirección de las parábolas principales en 15 días. Para que el acabado fuese perfecto, los tablones del encofrado estaban machihembrados. Se hormigonó con bomba, regando cuidadosamente el hormigón durante el tiempo de fraguado. El resultado puede verse entla figura 14. Los paraboloides se encuentran con el patio plateresco reedificado (figura 15), sin tocarlo, casi volando, para no perturbar su armoniosa ligereza.

http://informesdelaconstruccion.revistas.csic.es 


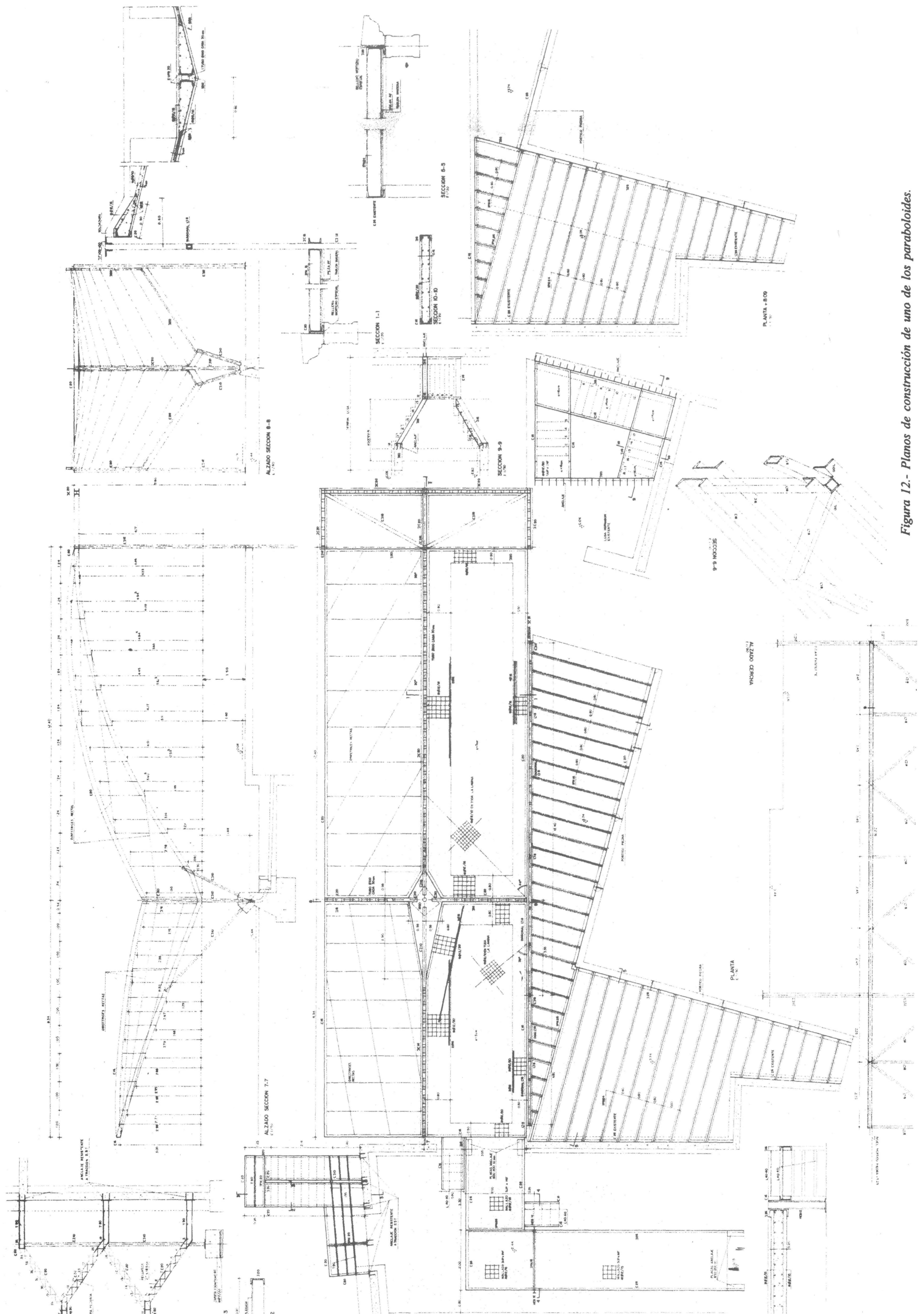

H 


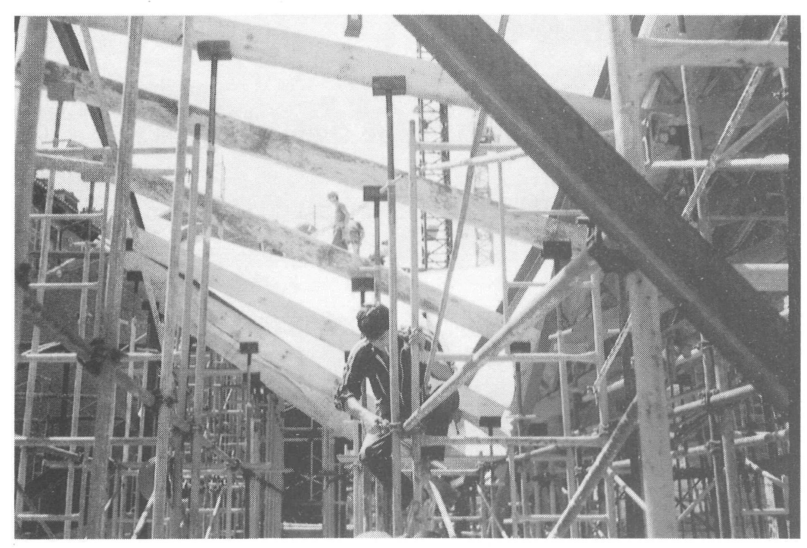

$\boldsymbol{a}$

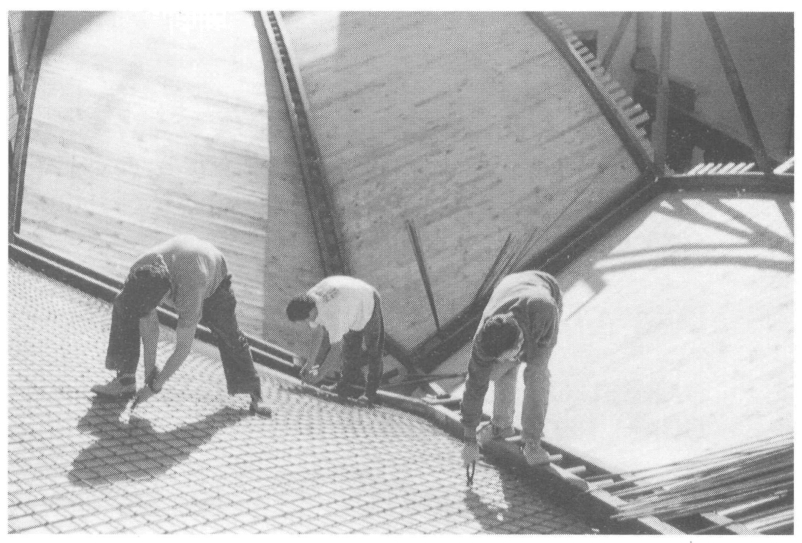

b

Figura 13.- Construcción de las láminas en paraboloide.
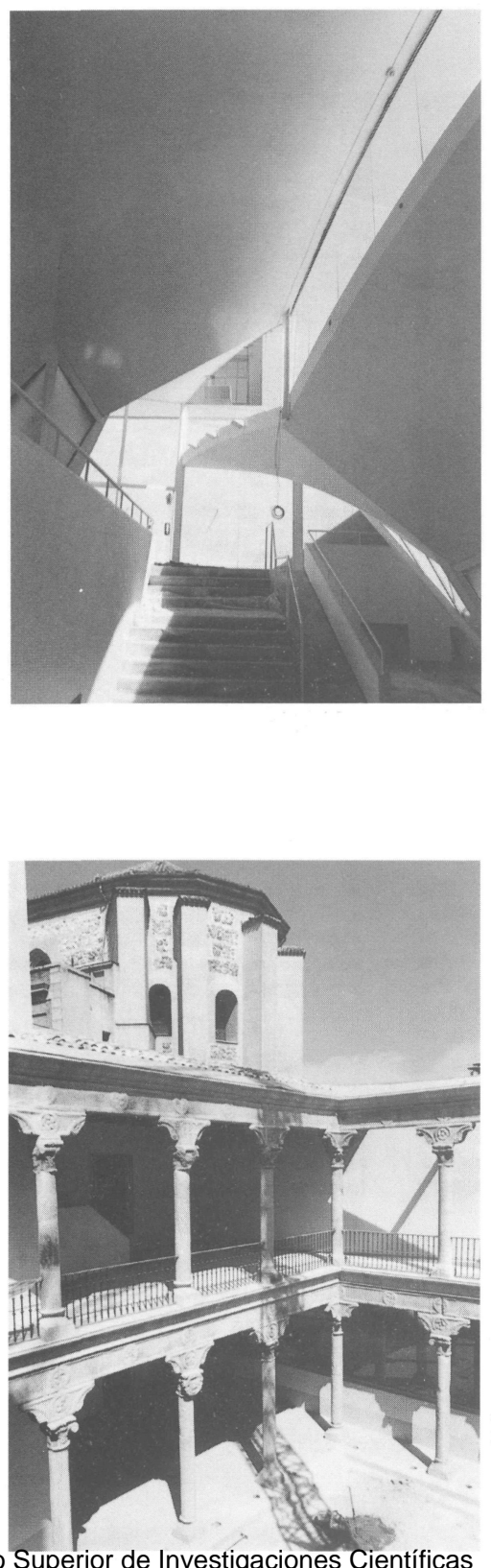

(c) Consejo Superior de Investigaciones Científicas Licencia Creative Commons 3.0 España (by-nc)

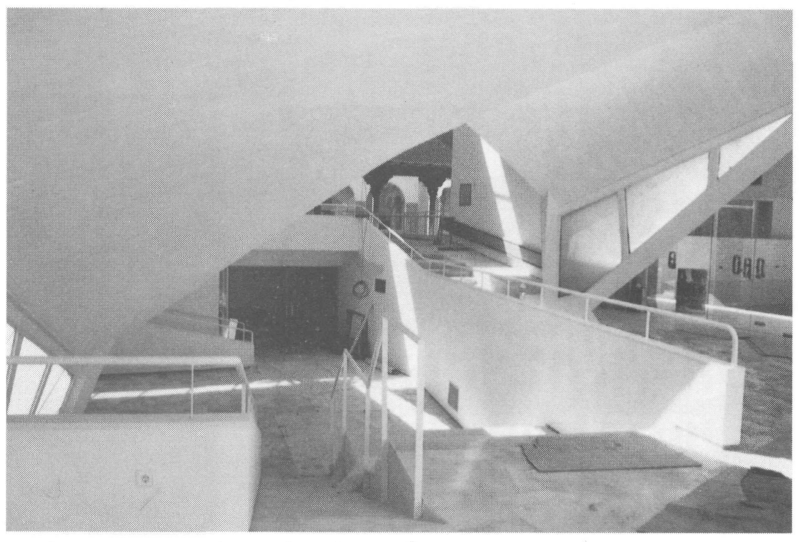

Figura 14.- Los paraguas curvos terminados.

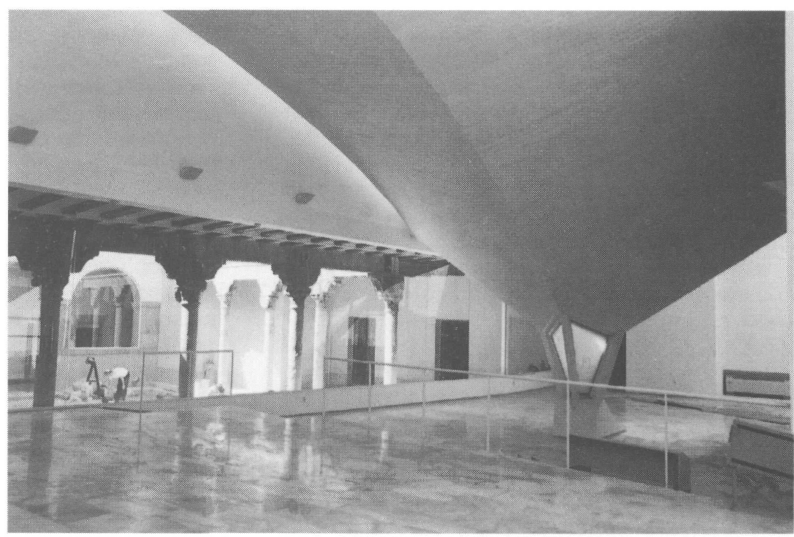

Figura 15.- El patio plateresco reedificado y el paraboloide contiguo. 


\section{REFERENCIAS}

[1] QUINTANA, JERÓNIMO DE LA. “A la muy antigua, nobley coronada Villade Madrid. Historiade su antigüedad, nobleza y grandeza". 1629. Ed. Facsímil. Ábaco Editores 1980. Libro Primero, páginas 233 y 234.

[2] IBIDEM. Libro Segundo, página 235.

[3] BARBEITO, JOSÉ MANUEL. "El Alcâzar de Madrid". COAM. 1992

[4] MESONERO ROMANOS, R. "El Antiguo Madrid" (1), página 78. Ed. Renacimiento. 1925.
[5] QUINTANA. IBIDEM. Libro segundo, página 286.

[6] FABER, COLIN. "Las Estructuras de Candela". CECSA. Méjico, 1970.

[7] QUINTAS RIPOLL, V. "Estructuras Especiales en Edificación. Análisis y Cálculo”. Parte segunda., páginas 383-384. Ed. Rueda. Madrid, 1996.

\section{Publicaciones del Instituto Eduardo Torroja-CSIC}

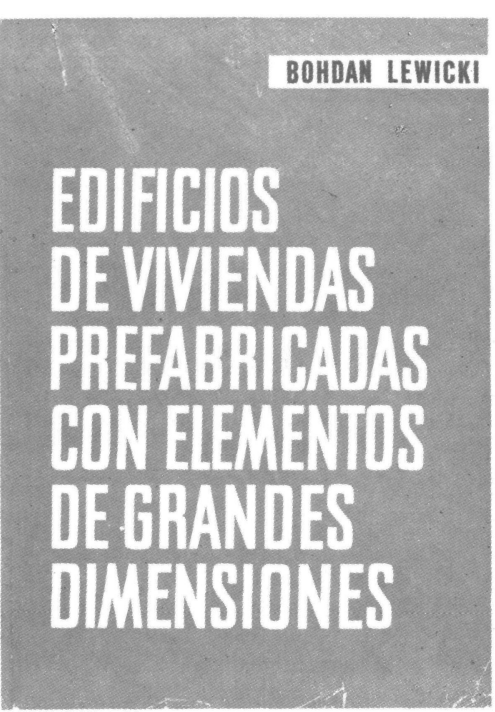

Bohdan Lewicki

Este libro trata de los problemas relativos a la construcción de los edificios de viviendas o publicos realizados con elementos prefabricados de grandes dimensiones. Se han estudiado los problemas de arriostramiento asi como los que plantea la resistencia de los elementos y de la estructura; se han examinado las cuestiones de orden higrotérmico, acústico y de resistencia al fuego: también se ha profundizado en el estudio de la estanquidad de los muros exteriores y de las juntas.

La obra incluye numerosas ilustraciones que dan detalles de diversas soluciones, as como ejemplos de cálculo, tablas de valores numéricos, diagramas y ábacos.

Un volumen encuadernado en tela, de $24 \times 17 \mathrm{~cm}$, compuesto de 616 págs.
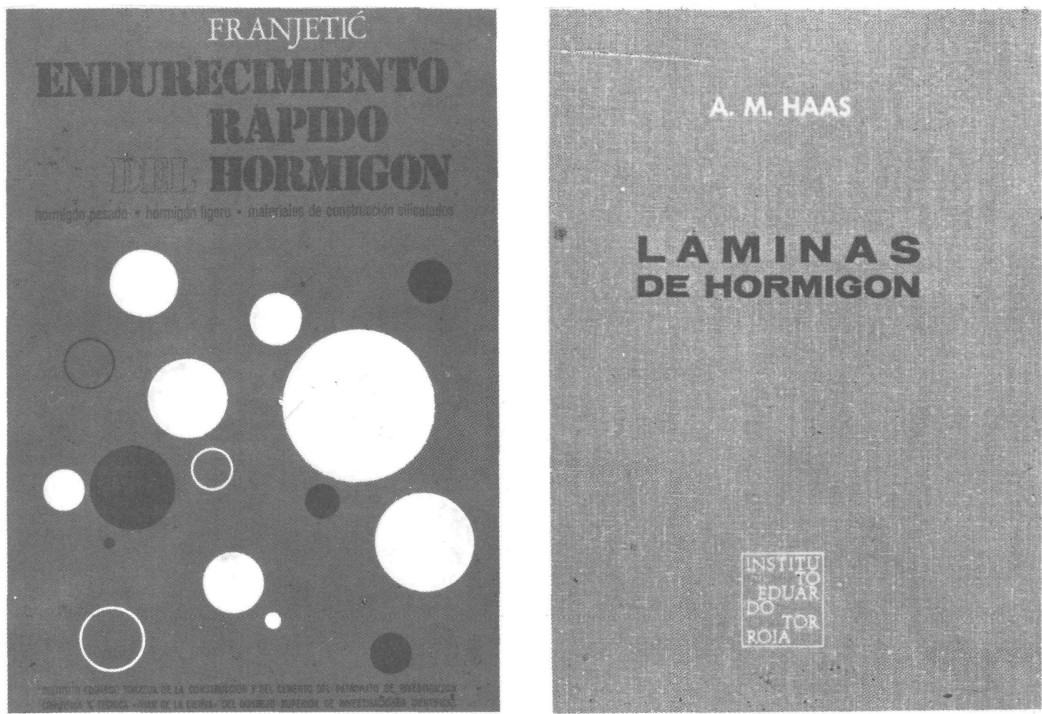

Zorislav Franjetić

En la obra de Franjetic se expone de una forma minuciosa ordenada y sistemática todo un cuerpo de doctrina que reúne el conocimiento actual sobre el endurecimiento nocimiento actual sobre el endurecimiento
rápido del hormigón. Parte el autor de los principios básicos y llega a las últimas consecuencias y realidades técnicas y economicas.

Es una obra de consulta, tanto para el investigador sobre la materia, como para e proyectista y el realizador y montador de plantas e instalaciones y equipos de curado y endurecimiento rápido.

Un volumen encuadernado en cartóné, de $17 \times 24,5 \mathrm{~cm}$, compuesto de 385 págs. 110 figuras y 10 tablas.

\section{A. M. Haas}

Al escribir este libro el autor intento poner a disposición de los estudiantes y de los ingenieros unos conocimientos prácticos, adecuados para servir de guia en el diseño y construcción de láminas delgadas de hormigón.

El autor está convencido de que el éxito en el diseño de una lámina exige, por parte del proyectista, un examen de las tres fases por las que pasa la materialización de la lámina: las que pasa la materialización de la lámina:
el diseño, el análisis estructural y la construcción de la estructura.

Un volumen encuadernado en tela de $17 \times 24,5 \mathrm{~cm}$, compuesto de 420 págs. 141 figuras, 22 fotografias y 6 tablas. 